\title{
Cyclone Sidr Impacts on the Sundarbans Floristic Diversity
}

\author{
Avit Kumar Bhowmik ${ }^{1} \&$ Pedro Cabral $^{2}$ \\ ${ }^{1}$ Institute for Environmental Sciences, Quantitative Landscape Ecology, University of Koblenz-Landau, \\ Germany \\ ${ }^{2}$ Instituto Superior de Estatística e Gestão de Informação, ISEGI, Universidade Nova de Lisboa, Portugal \\ Correspondence: Avit Kumar Bhowmik, Institute for Environmental Sciences, Quantitative Landscape Ecology, \\ University of Koblenz-Landau, Fort Straße 7, D-76829 Landau in der Pfalz, Germany. Tel: 49-6341-280-31331. \\ E-mail: bhowmik@uni-landau.de
}

Received: July 12, 2012 Accepted: August 17, 2012 Online Published: March 8, 2013

doi:10.5539/esr.v2n2p62 URL: http://dx.doi.org/10.5539/esr.v2n2p62

\begin{abstract}
The Sundarbans - the world's largest single block of tidal halophytic mangrove forest situated at the southwest of Bangladesh, plays a vital role in maintaining environmental sustainability of the country and the world in general. This study identified and quantified the extent and degree of damage caused to the floristic diversity of the Sundarbans by the tropical cyclone Sidr in 15 November 2007. It also quantified the extent and rate of the post-cyclone regeneration in the damaged flora. Unsupervised classification - ISODATA and the normalized difference vegetation index (NDVI) were carried out over a temporal series of 2007-2010 on four Landsat 7 Enhanced Thematic Mapper Plus (ETM +) images for the months of February. Land change analysis from the classification results show that three important floristic taxa - Heritiera fomes (Sundari), Excoecaria agallocha (Gewa) and Sonneratia apetala (Kewra) have been significantly affected by the cyclone. NDVI analysis indicates that $45 \%$ area of the Bangladesh's part of the Sundarbans (approximately 2500 sq.km) was affected due to the cyclone action. Results further indicated that the average rate of post-cyclone floristic growth in 2009-2010 is four times higher than the average rate in 2008-2009. Thus the study identified a temporary loss of the diversity (in terms of relative abundance) in the affected three floristic taxa of the Sundarbans after that severe exogenous perturbation; which took three years to regenerate. Moreover, it showed the higher efficiency and promptness of remote sensing techniques in similar cases than the ground data based studies.
\end{abstract}

Keywords: environmental sustainability, floristic diversity, cyclone, remote sensing, unsupervised classification, NDVI

\section{Introduction}

The biodiversity and its conservation have been established as the primary indicators of environmental sustainability (Kates et al., 2001), whereas the assessment of biomass and floristic diversity in tropical forests has been identified as a priority by many international organizations (Stork et al., 1997). Research concerned with monitoring environmental resources have shown the advantages of using remote sensing for studying environmental sustainability (Eastman \& Fulk, 1993; Fensholt et al., 2009; Foody, 2003; Galford et al., 2008; Rogan \& Chen, 2004; Skidmore et al., 1997). It is an emerging issue that how the remote sensing technique can be best applied to identify patterns of floristic diversity on the Earth's surface and to detect changes in them over time (Brink \& Eva, 2009; Wood et al., 2002). Remote sensing has been efficiently used in forest cover mapping (Chuvieco \& Congalton, 1989), biomass and floristic diversity prediction (Gibbs et al., 2007) along with the estimation of potential impacts of severe exogenous perturbation (Dahdouh-Guebas, 2002). Remote sensing is applicable for detecting changes in the composition and distribution of flora in a forest that has experienced the impact of exogenous perturbation such as droughts, cyclones, wind, floods, rain erosion, etc., as well as of man-made encroachment (Fuller, 2006; Mumby et al., 1999).

Tropical cyclones have devastating impacts on the floristic diversity pattern of tropical mangrove forests; sometimes it takes a significant amount of time for the forest to regenerate which influences the environmental sustainability of the area (Elsner et al., 2008). They can cause temporary or permanent absence in the number and relative abundance of particular floristic taxa. Baldwin et al. (2001) state that the time required for the regeneration of mangrove forests following cyclones depends on the different pathways. The pathways are 
generally produced by the complex interactions between resprouting capability, seedling survival, post-hurricane seedling recruitment, and colonization by herbaceous vegetation. The time required for regeneration also depends on the degree of damage; Nayak et al. (2001) analyses the impact of cyclone on the mangrove forest in the coastal region of Orissa, Inida. The NDVI analysis of the study shows that mangroves were not totally uprooted but had shed their leaves and within two months, the mangroves have reached their original state. There are multiple stable states for flora in tropical mangrove ecosystems and, therefore, the floristic diversity status can sensitively reflect the environmental and ecological variation caused by cyclones (Hussain \& Ahmed, 1994). Consequently, the degree of destruction of the flora due to cyclones is the most direct indicator of floristic diversity degradation in the mangrove forest which can be identified applying remote sensing techniques. The extent of damage due to the cyclone and initial regeneration of the forest from the damaged state can also be identified using remote sensing techniques (Andrew \& Elmore, 2000). In particular, the Normalized Differential Vegetation Index (NDVI) (Rouse et al., 1973) is frequently used to assess the green biomass condition in the vegetation over time (Barrett et al., 1999; Tucker, 1979; Li et al., 2010; Julien et al., 2011; Lin et al., 2003). Additionally, the classification of floristic types using satellite images obtained in different time steps can be used to study changes in the flora over time (Salovaara et al., 2005; Wolter et al., 1995). Prior remote sensing studies (Giri et al., 2007; Emch \& Peterson, 2006) have provided with accurate and constructive results for analyzing the change in the floristic pattern of the Sundarbans. In most cases these studies were quicker and more efficient than the ground data based studies in producing results.

This study identifies the degree of damage and quantifies the extent of damage of the floristic diversity of the Sundarbans caused by the tropical cyclone Sidr in 15 November 2007 applying remote sensing techniques. The rate and extent of post-cyclone regeneration have also been quantified. This study aims at three objectives: (i) to identify the changes in the floristic pattern of the Sundarbans, in the preceding and following periods of the tropical cyclone Sidr; (ii) to identify specific floristic damage caused within the catchment extent of cyclone trajectory and their regeneration until year 2010; and (iii) to identify the relevance of the study results when comparing to previous ground data based studies about the Sidr effect on the Sundarbans (CEGIS, 2007; Hasegawa, 2010; Hossain \& Begum, 2011; Paul \& Dutt, 2010; Paul, 2009; Shamsuddoha \& Chowdhury, 2007).

\section{The Sundarbans and the Sidr Cyclone}

The Sundarbans is the largest single block of tidal halophytic mangrove forest in the world. The forest lies to the vast delta on the Bay of Bengal formed by the confluence of the Ganges, Brahmaputra and Meghna rivers across Bangladesh and West Bengal, India (Figure 1(a)) (Iftekhar \& Islam, 2004). The seasonally-flooded Sundarbans' freshwater swamp forests lie inland from the mangrove forests on the coastal fringe. The mangrove forest covers $10,000 \mathrm{sq} . \mathrm{km}$. in total, of which about 6,000 sq.km. is in Bangladesh. It has been inscribed as a UNESCO world heritage site in 1997 (Gopal \& Chauhan, 2006). The Sundarbans is intersected by a complex network of tidal waterways, mudflats and small islands of salt-tolerant mangrove forests (Figure 1(a)). The dominant mangrove floristic taxon Heritiera fomes, locally known as Sundri or Sundari, is the floristic taxon for which the Sundarbans is thought to be named. It has a thick canopy and the undergrowth is mainly composed of seedlings of mangrove trees. The mangrove forest is made up of the diverse floristic taxa that grow in saline coastal soils of tropical and subtropical areas. The mangrove taxa that build up this forest's floristic diversity include Avicennia spp., Xylocarpus mekongensis, Xylocarpus granatum, Sonneratia apetala, Bruguiera gymnorrhiza, Cereops decandra, Aegiceras corniculatum, Rhizophora mucronata, and Nypa fruticans palms (Komiyamaa et al., 2008). The area is also renowned for the eponymous Royal Bengal Tiger (Panthera tigris tigris), as well as for other numerous fauna including species of birds, spotted deer, crocodiles and snakes (Chaudhuri et al., 1994).

The southern coastal region of Bangladesh is one of the most frequently affected regions by tropical cyclones. The potential periods for the occurrence of cyclones are the pre-monsoon and post-monsoon (April-May, November-December). The most important recent tropical cyclone that hit the coast of Bangladesh in 2007 is called 'Sidr' and it made landfall on 15th of November with peaking wind speed of over $220 \mathrm{~km} / \mathrm{h}$. It resulted in an estimated 4000 human deaths and the displacement of over 3 million people (US Embassy Dhaka, 2007). The most significant devastating impact it left behind is on the diversity of flora of the Sundarbans. One quarter of the biomass cover (which is approximately $2500 \mathrm{sq} . \mathrm{km}$ ) of the Sundarbans mangrove forest was damaged by the storm directly or indirectly due to the tidal surge (CEGIS, 2007). In Figure 1(b) the trajectory of the cyclone is shown, where the red line represents the changing location of the eye of the storm. Since the eastern part of the Sundarbans has largely been affected by the cyclone Sidr because of the proximity to the cyclone trajectory, the study area has been selected accordingly. The study area is located in the south-westernmost part of Bangladesh, adjacent to the Indian border (Figure 1). 


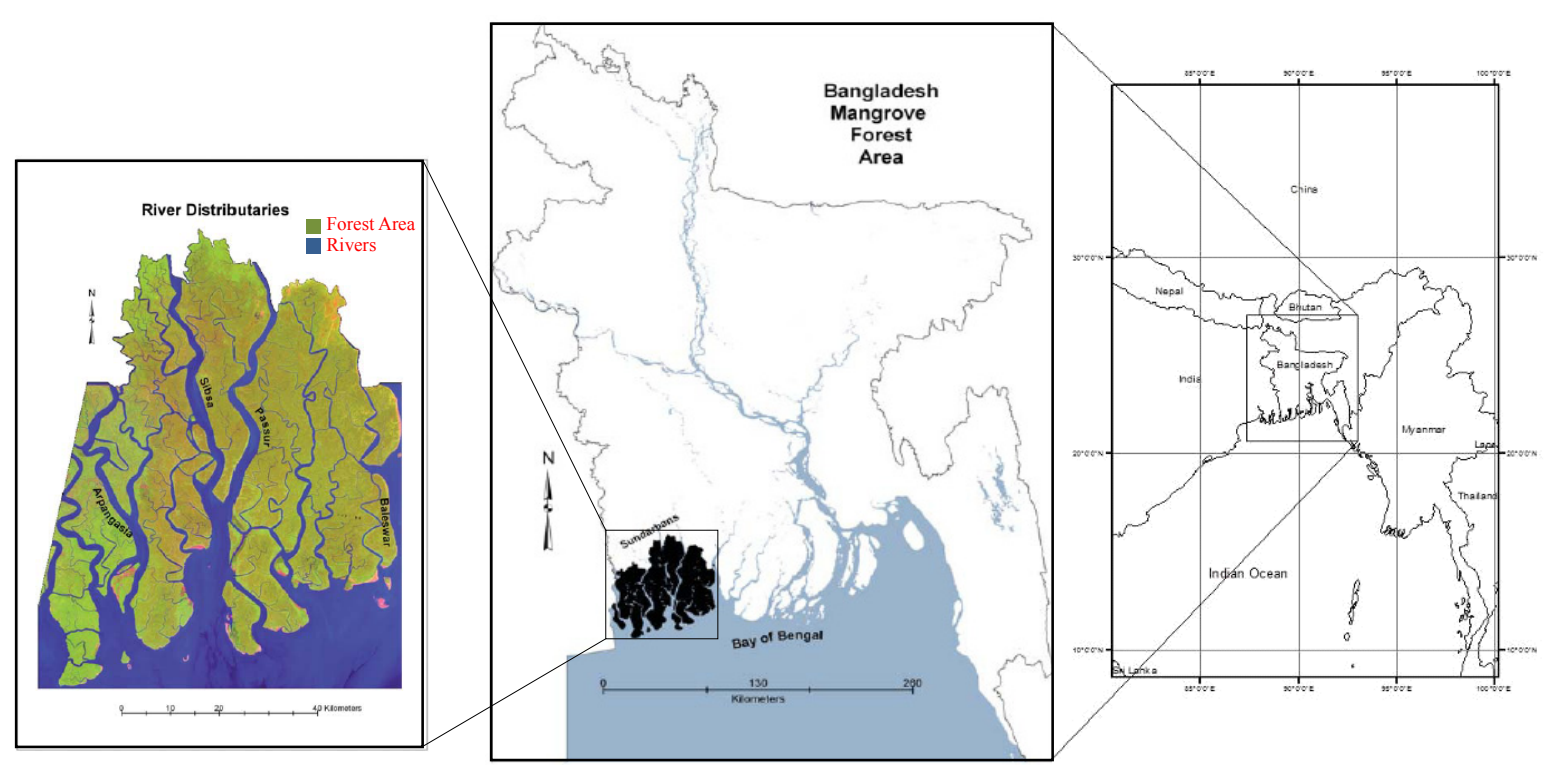

(a)

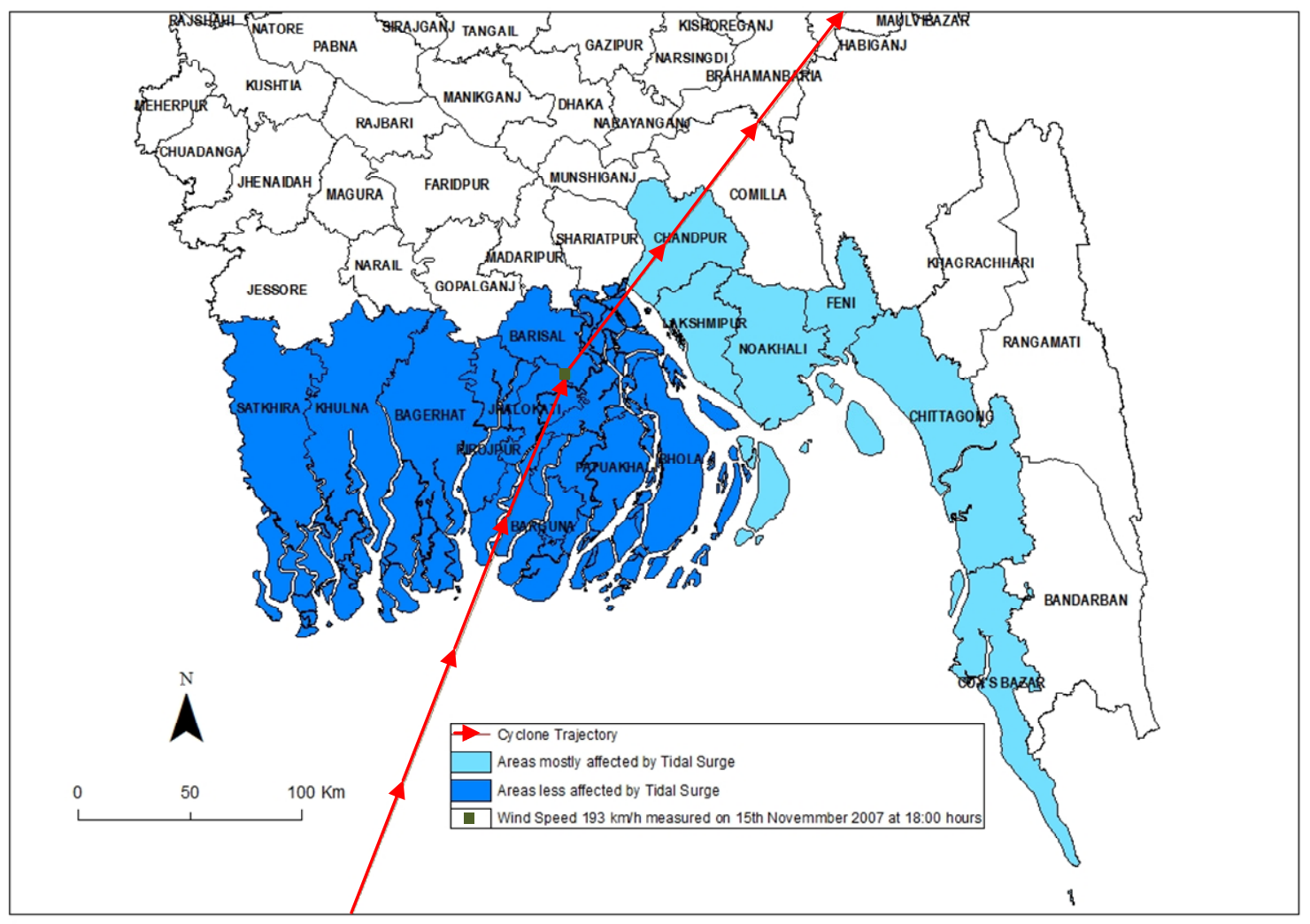

(b)

Figure 1. (a) Location of the Sundarbans Mangrove Forest with river distributions and forest area (Emch \& Peterson, 2006); (b) Cyclone Sidr trajectory and affected areas (CEGIS, 2007)

\section{Materials and Methodology}

\subsection{Satellite Data}

The satellite images used in this study are from Landsat 7 ETM + . Two scenes from Landsat 7 ETM + are required to cover the Bangladesh's part of the Sundarbans mangrove forest. The satellite images are freely 
available at USGS (2010). The reason for choosing this particular sensor image is the availability of the relatively recent (02 February 2008) free satellite image of the post-cyclone period (after November 15, 2007) of Sidr. Landsat $5 \mathrm{TM}+$ also provides with the free satellite images of the Sundarbans area, but the latest image available from this sensor for the post-cyclone period is of 02 June 2008. Additionally, the availability of the image on regular anniversary dates to minimize errors due to seasonal differences and atmospheric conditions, e.g. cloud cover, is also considered. Seasonal differences can have an important influence on land cover and especially NDVI analyses because photosynthetic activities of flora change with the season (Jensen, 2004). However, the first clear image that became available for the pre-cyclone period (before November 15, 2007) is from 15 February 2007. Thus the Landsat 7 ETM+ images obtained on 15 February 2007, 02 February 2008, 04 February 2009 and 07 February 2010 (USGS, 2010) are selected for the study. The bands 1, 2, 3, 4, 5 and 7, which have a 30 meter spatial resolution, are employed in the image classification process. In the visualization of the results, only the cyclone Sidr landfall area is presented using WGS 84 coordinate system for a better visual comparison.

\subsection{Image Pre-processing}

The Landsat 7 ETM+ images used in this study have a serious detector response error of periodic line dropout. Mask bands corresponding to each of the bands are used to minimize this error. The mask bands are combined during the production of the multi-band images and, the images with minimized periodic line dropout error, are used for further analysis. Contrast stretching with histogram equalization is applied to each image for radiometric enhancement (Conghe, 2001).

\subsection{Unsupervised Classification}

An unsupervised classification is carried out for each of the orthorectified images to distinguish among different groups (clusters) of floristic taxa of the study area in different years; thus to identify which types were more affected by the cyclone and which of them regenerated faster. It is not possible to distinguish between every single taxonomic type of flora with the available spectral resolution of the satellite images. The satellite image quality and the problem of periodic line drops also affected the identification of taxonomic types in detail. The vegetation map (Mohaiman et al., 2002) of the Sundarbans provided by the Forest Department of Bangladesh is used as an auxiliary dataset to create the clusters.

ERDAS IMAGE ${ }^{\circledR} 9.1$ (ICPHG, 2012) is used to run the unsupervised classification algorithm - Iterative Self-Organizing Data Analysis Technique (ISODATA). This technique is based on the k-means algorithm, which minimizes the variability within clusters of pixels (Yale University, 2010). The basic function of performing the classification is as equation (1):

$$
S S_{\text {distances }}=\sum_{\forall x}[\mathrm{x}-\mathrm{C}(\mathrm{x})]^{2}
$$

where,

$S S_{\text {distances }}$ - stands for the square distance (error) between each pixel and its assigned cluster centre,

$\mathrm{x}-$ is the position of the centre of each pixel,

$\mathrm{C}(\mathrm{x})$ - is the position of the cluster centre of the pixel $\mathrm{x}$.

The value to be minimized is the sum of squared distances between each pixel and its assigned cluster centre. After assigning a random initial cluster vector, pixels are classified to the closest cluster. Six iterations are used in this process so that the variability within the cluster becomes smaller and less pixels change with every following iteration. Since the auxiliary dataset used for the process provides 17 classes of floristic taxa of the Sundarbans and one class for water body, the number of classes of the pixels with different spectral signatures to be resulted by ISODATA process is set to 20 . The resulted classified imageries are then clustered based on homogeneity to five classes because five identical clusters can be distinguished from Mohaiman et al. (2002). This process is carried out with all the four images of the four different years and thus four classified images of the four different years are produced for further analyses of damage and regeneration (Figure 2).

\subsection{Normalized Difference Vegetation Index (NDVI)}

NDVI is a calculation, based on several spectral bands, of the photosynthetic output of a pixel in a satellite image (Rouse et al., 1973). The calculation is carried out with the images of the Sundarbans of the four different years to identify the general health of the flora before and after the cyclone Sidr made landfall, and to analyze the 
degree and extent of damage and rate of regeneration.

NDVI calculations are based on the principle that actively growing green plants strongly absorb radiation in the visible region of the spectrum (the 'PAR' or 'Photosynthetically Active Radiation') while strongly reflecting radiation in the Near Infrared (NIR) region. The concept of vegetative 'spectral signatures (patterns)' is based on this principle. In this study, the modification are made by using only the Red image band instead of the whole range of PAR because of the available spectral resolution of the satellite images. Thus, the NDVI is calculated by equation (2).

$$
N D V I=(N I R-R e d) /(N I R+R e d)
$$

This formula yields a value that ranges from -1 (usually water) to +1 (strongest vegetative growth). ArcGIS 9.3.1 (ESRI, 2012) has been used with the NDVI calculator tool to calculate the NDVI value of each pixel of the orthorectified images. Since band 4 represents the NIR band and band 3 represents the Red band in Landsat 7 $\mathrm{ETM}+$, these two bands are used to calculate the NDVI. The process results in four different maps of the four different years with different NDVI values in different regions (Figure 4). The NDVI values are classified and grouped according to the natural breaks of their frequencies in the processed Landsat image of 2007, and similar classes are maintained in the NDVI images of the remaining years to obtain a better evaluation of damage and regeneration. In general the images (Figure 4) show values close to -1 for the rivers inside the Sundarbans and values close to +1 for the mangrove vegetation.

\subsection{Analyses of Damage and Regeneration}

Descriptive statistics (Oja, 1983) is applied to calculate the degree and extent of damage and rate of regeneration in the preceding and following periods of the cyclone Sidr. The frequency distributions of the pixels under different taxonomic clusters for unsupervised classified images, and under different NDVI value groups in the images are analyzed. The corresponding numbers of pixels for the taxonomic clusters and NDVI groups are multiplied by the spatial resolution $(30 \mathrm{~m})$ of the pixels to calculate the covered area under each taxonomic cluster and each NDVI group. Thus the calculated areas of different taxonomic clusters and different NDVI groups from the images of the four different years are compared to find out the extent and degree of damage and the regeneration. The changes in the regenerated area are also computed to find out the rate of regeneration in each year.

\subsection{Accuracy Assessment}

Accuracy is considered to be the degree of closeness of results to the values accepted as true reference. Accuracy assessment technique allows for measures to describe the accuracy of the classified images with respect to the reference images. The procedure includes four major steps - collecting reference data which is considered as 'ground truth', determining class types at specific locations, comparing reference to classified map and evaluating whether class type on classified map is conformal to the class type determined from reference data (Khorram et al., 1999). Some recognized sources of reference dataset are aerial photo, ground truth with Global Positioning System (GPS) and Geographic Information Systems (GIS) layers etc. The vegetation map of the Sundarbans (Mohaiman et al., 2002) is the only ground truth reference available for the accuracy assessment of the classified and NDVI images. Since the map was created in 2002, only the produced classified and NDVI images of February 2007 are assessed for accuracy with this reference database. The images of 2007 are assumed to be more analogous to the reference map of 2002 than the images of other years. In addition, the Google Earth image (USSG, 2010) of the Sundarbans of 2010 is used as reference database to assess the accuracy of the classified and NDVI images of February 2010, in order to compensate the unavailability of ground truth. The accuracy of the images from 2007 and 2010 are assumed to be close to the images from 2008 and 2009 for which no accuracy assessment is carried out due to the lack of ground truth data.

Generally, a confusion matrix (Story \& Congalton, 1986) is prepared to represent the number of pixels classified as a particular landuse or vegetation type in a classified image and number of pixels assigned to that particular landuse or vegetation type in light of the reference database. It also contains the information about the number of pixels that are classified accordingly to the reference dataset and the number of pixels that are classified otherwise. Three different primary accuracies are calculated to quantify the assessment - Overall Accuracy, Producer Accuracy and User Accuracy (Janssen \& Van der Wel, 1994). The overall accuracy is calculated by dividing number of correct pixels with total number of pixels; but since this summary value is an average and does not reveal if error was evenly distributed between classes or if some classes were really bad and some were really good, producer accuracy and user accuracy are calculated. Producer accuracy corresponds to error of omission (exclusion), which is calculated by dividing number of correctly identified pixels in the classified image of a given class by number actually in that reference class. On the other hand, user accuracy corresponds 
to error of commission (inclusion) which is calculated by dividing number correctly identified in a classified image by number claimed to be in that class of the image. These three accuracy measures provide with the primary accuracy of the classified image and thus reflect the quality of the observation and analysis using the image (Liu et al., 2007).

For the preparation of the confusion matrices, 50 sample pixels are set with the same locations in the classified images and in the reference maps. The spectral signatures for each pixel of the classified images and reference maps are compared and the confusion matrix is prepared. Pixel information in the rows corresponds to that of the reference map and the columns show the pixel information that resulted from the unsupervised classification and NDVI calculation.

\section{Results}

\subsection{Unsupervised Classification}

From the classified image of February 2007 (Figure 2), a clear distinction is visible between the areas of the two main taxonomic clusters of flora when compared to Mohaiman et al. (2002). On one hand, floristic taxon cluster 1, which mainly consists of Passur (Xylocarpus menkongensis), Goran (Ceripos tegal) and Baen (Avicennia marina $L$.), covers the western part of the Sundarbans. On the other hand, floristic taxon cluster 2, which consists mainly of Sundari (Heritiera fomes), Gewa (Excoecaria agallocha) and Kewra (Sonneratia apetala), covers the eastern part of the Sundarbans. Since the trajectory of cyclone Sidr passed through the eastern part of the Sundarbans, cluster 2 is likely to be affected by the cyclone landfall. The fallow land and other vegetation are evenly distributed in the Sundarbans area but most of them also covered the area near the cyclone trajectory.

The classified image of 2008 (Figure 2), shows the expected result - a significant decrease in cluster 2 in the eastern part of the Sundarbans dominantly in the catchments of the cyclone trajectory. The spectral signature of cluster 2 of this area from the classified image of February 2007 is replaced by the spectral signature of fallow land. Though this signature is obtainable from the areas corrected from periodic line drops, it is not taken into account since the result could be misleading. The spectral signature of other floristic taxa from 2007 of the area near the cyclone trajectory is also replaced by the signature of fallow land. So, from the primary analysis, it can be stated that cluster 2 is the most affected floristic taxon cluster by the cyclone Sidr, i.e floristic species Sundari, Gewa and Kewra are mostly damaged by the cyclone Sidr.

On the other hand, there is a growth of spectral signature of cluster 1 in the western part of the Sundarbans from February 2007 to February 2008. It is not possible to comment on this observation concretely because of the available spectral resolution of the image, but in light of Mohaiman et al. (2002), the classified image of February 2007 does not reflect cluster 1 in the western part to the full extent. It is most likely that those species of cluster 1 experience a high growth rate and are not affected by cyclone Sidr, and eventually grow to its full extent. The ground data based studies (Hasegawa, 2010; Shamsuddoha \& Chowdhury, 2007) result in conformal observation.

The classified image of 2009 (Figure 2) shows a comeback of the cluster 2 in the eastern part of the Sundarbans which is clearly an indicator of regeneration process which had started after the cyclone landfall. In contrary, the spectral signature of cluster 1 almost disappears from the classified image of February 2009. Again, the spectral resolution of the image is not adequate to discuss the reason, but Hossain and Begum (2011) mentioned some activities of the local 'wood pirates' and eventual destruction of the species of cluster 1 . The source of their information is local interviews. Additionally, Landsat imageries generally absorb the canopy signature from a forest and there is a significant effect of the natural phenomenon like precipitation on the canopy health. Thus, the piracy explains the result to some extent but there should be other reasons which are subject to future studies. The classified image of February 2010 (Figure 2) shows a regeneration of the cluster 1 and static state of cluster 2 in the Sundarbans when compared to the classified image of February 2009. The distribution of the floristic taxon clusters appear to be similar to the one from the classified image of February 2007 i.e. pre-cyclone period though cluster 1 seems still vulnerable. It can be claimed from the primary analysis that there is a complete regeneration of the forest from the cyclone Sidr effect in 2010.

To quantify the degree and extent of damage of a particular vegetation type due to cyclone Sidr, the descriptive statistical analysis is performed on the pixels derived from Figure 2. Figure 3 shows the frequency distribution of the pixels of the unsupervised classified images of four different years with the changing ratios between the pixel coverage of land cover types of the study area between 2007 and 2010. In the classified image of 2007, there is the dominating pixel coverage (almost count 2,200,000) of the cluster 2. But in the images of 2008, there is a significant decrease in this particular pixel coverage (almost count 400,000), and an increase in fallow land pixel coverage (from almost count 600,000 to around count 1,400,000), which clearly represents the damage caused 
by the cyclone. Moreover, the flourishing cluster 1 is also represented by the corresponding pixel coverage change (from around count 800,000 to count $2,100,000$ ). Also the other floristic taxa decreased from around count 200,000 to count 100,000 in between 2007 and 2008 .

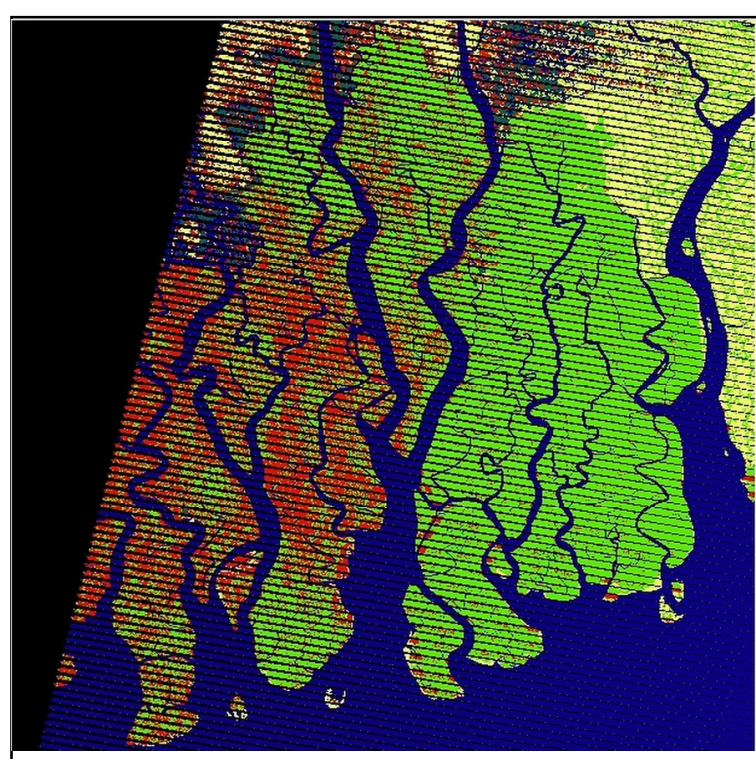

2007

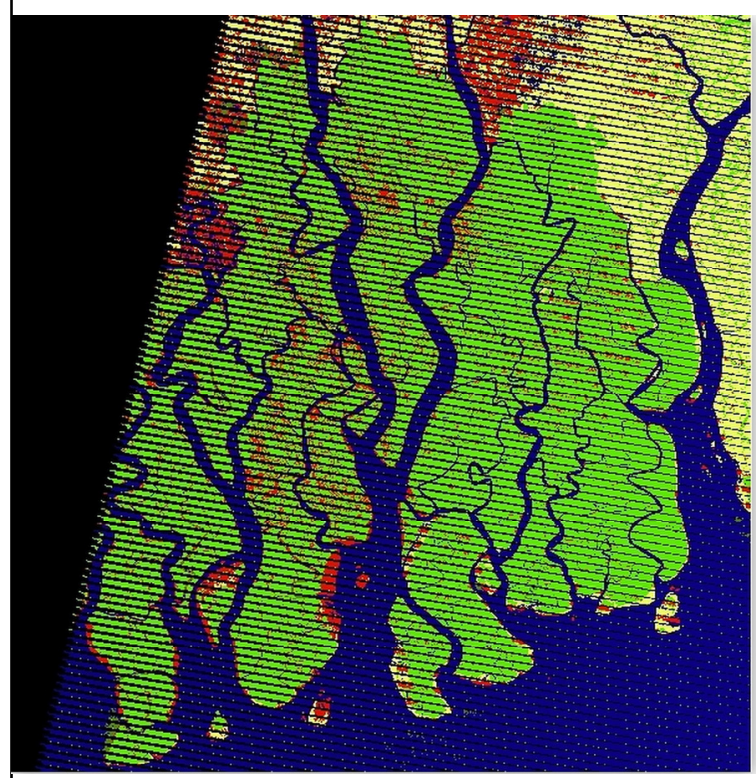

2009

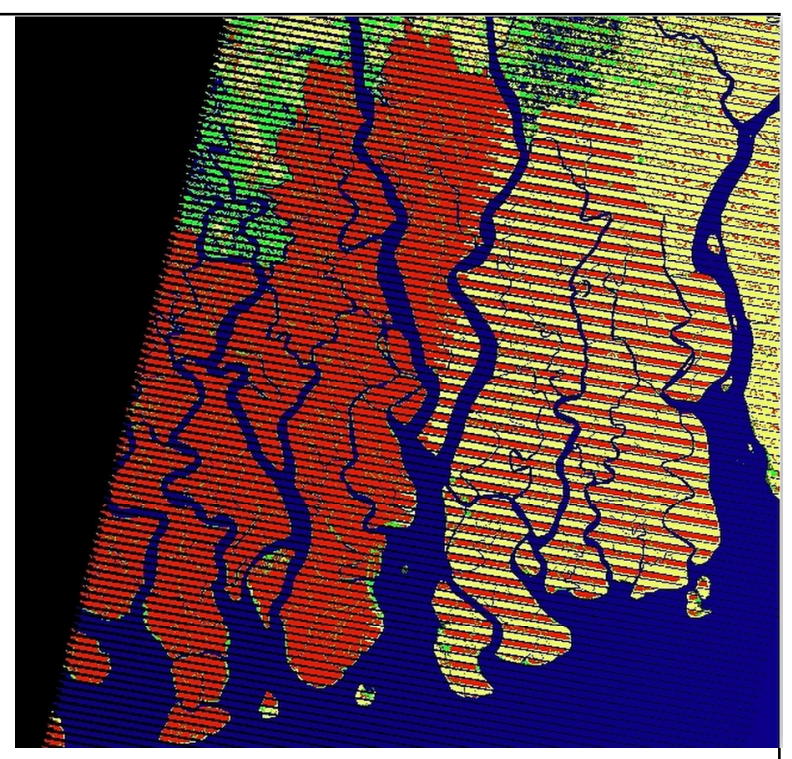

2008

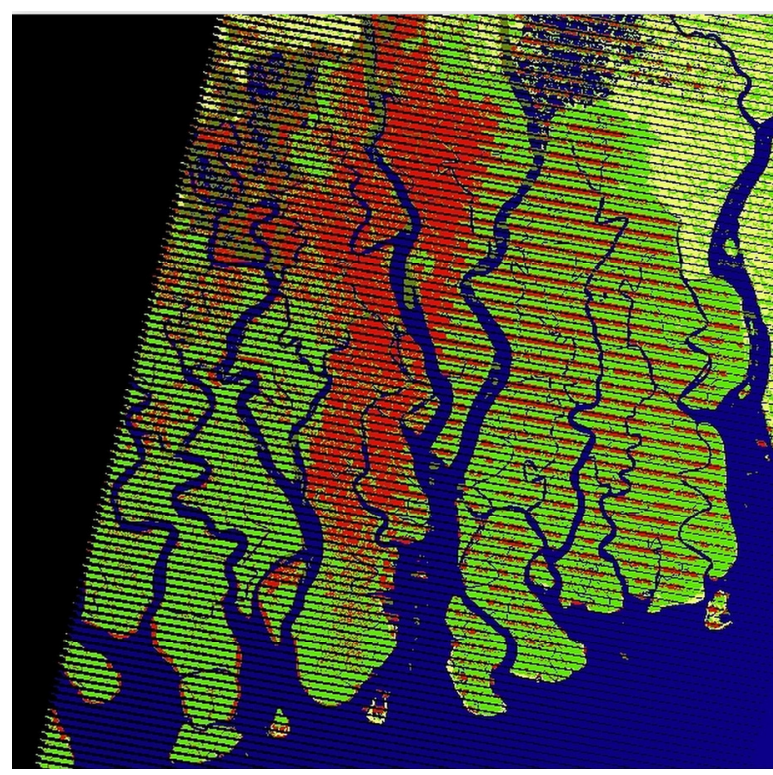

2010

\begin{tabular}{|lllll}
\hline Geographic Coordinate System: GCS WGS 1984 & No data \\
Other Floristc Taxa
\end{tabular}

Figure 2. Classified map of the Sundarbans land cover of February 2007, 2008, 2009 and 2010 
The frequency distribution of the classified image pixel coverage (Figure 3) of 2009 and 2010 represents the regeneration of the Sundarbans flora after the cyclone. In 2009, the pixel coverage of the affected cluster 2 is dominantly increased (to almost count 2,600,000) and the fallow land pixel coverage decreased (to around count $600,000)$. And in 2010, the distribution of the pixel coverage of different vegetation types appears to be very similar to the one of 2007. There is a regeneration of the cluster 1 which is also visible (from around count $450,000$ to almost count $1,200,000)$. This represents the complete regeneration of the Sundarbans flora from the cyclone damage.

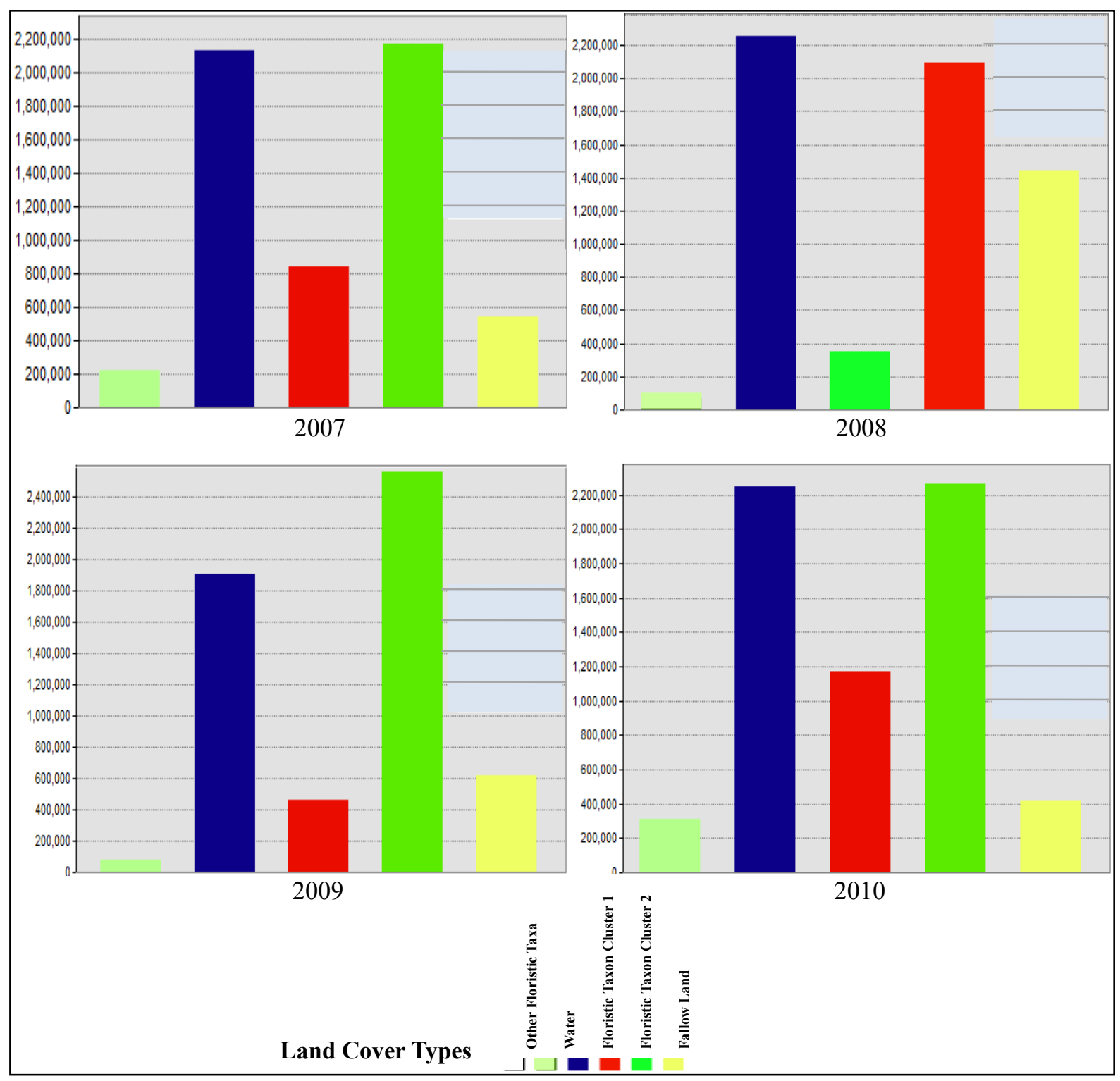

Figure 3. The frequency distribution of the pixels assigned to each unsupervised floristic taxon cluster in February 2007, 2008, 2009 and 2010

The area coverage of the different floristic types of the Sundarbans during the pre and post cyclone period is presented in Figure 4. In light of the results presented before, the decrease in the area covered by the cluster 2 and other floristic taxa from 2007 to 2008 mainly represents the extent of damage caused by cyclone Sidr to the Sundarbans floristic diversity. The decrease in the extent of the cluster 2 is 1620 sq.km. (from 1962 sq.km. to 342 sq.km.), whereas the decrease in the extent of other floristic taxa is 108 sq.km. (from 198 sq.km. to 90 sq.km.) according to the results. Therefore the total extent of the damage according to the unsupervised classification is 1728 sq.km. with the specific damage to the floristic taxon types of Sundari, Gewa and Kewra. 
The degree of damage cannot be identified from unsupervised classification, consequently the study lead to the NDVI analysis to quantify the degree of damage with a precise extent of damage. Moreover, quantifying the rate and extent of regeneration is also difficult from the unsupervised classification, because it does not reflect the floristic health. But it can be identified that by 2010 , the mangrove forest is recovered from the cyclone damage and specifically the damage in the floristic taxon cluster 2 is recovered by 2009 .

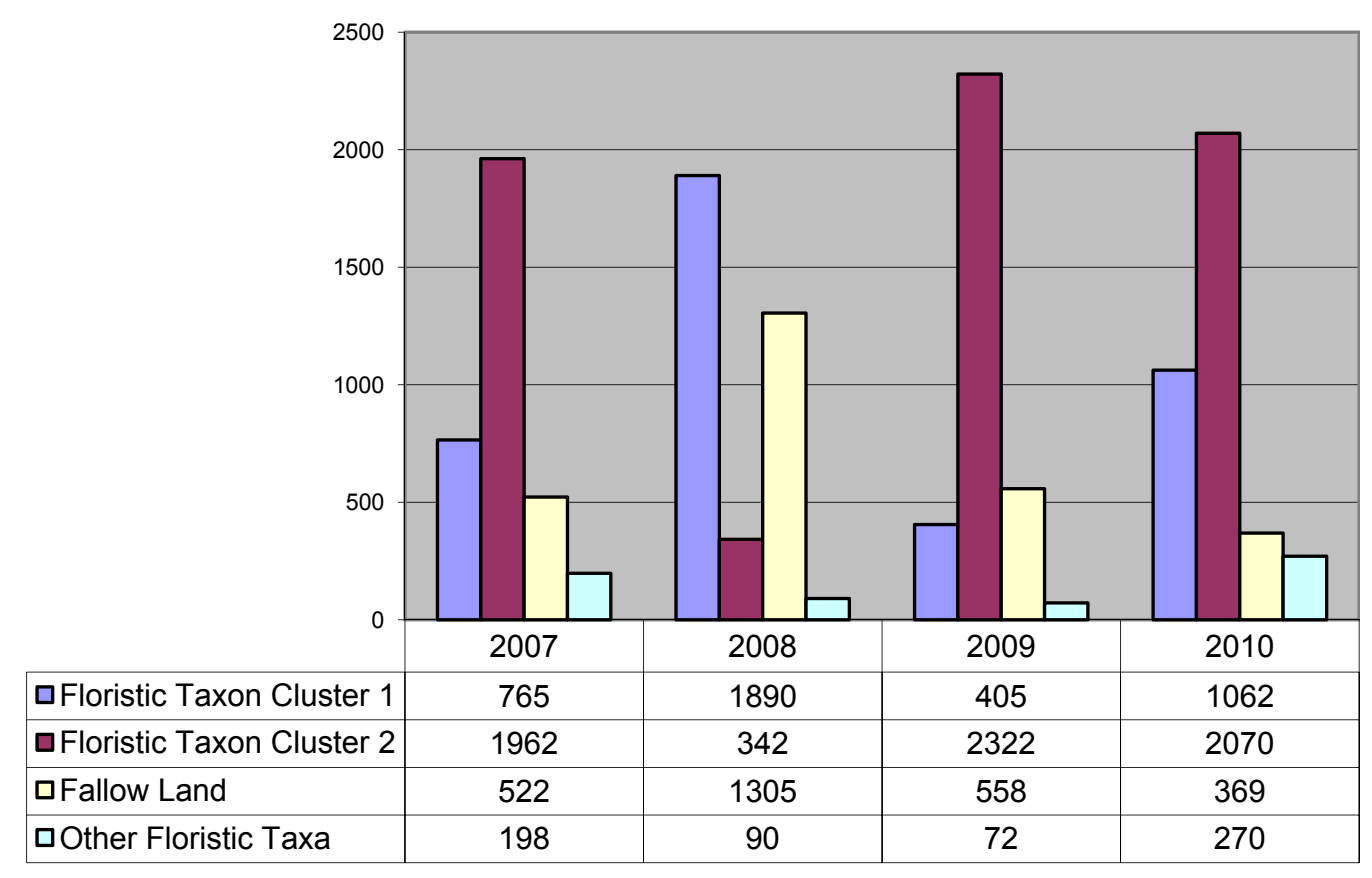

Figure 4. The area coverage of different floristic taxa (in sq. km.) resulted from the unsupervised classification of the images of February 2007, 2008, 2009 and 2010

\subsection{NDVI Analyses}

The calculated NDVI images of four different years (Figure 5) quantify the extent of the damage caused by cyclone Sidr at the eastern part of the Sundarbans. The NDVI value at the eastern part of the Sundarbans is decreased significantly from 2007 to 2008 in contrast to the increased value in the rest of the area. In light of the highly increased NDVI value at the western part of the Sundarbans from 2007 to 2008, the eastern region would experience higher NDVI value than the western region if the cyclone would not have made landfall. Therefore, the vegetation health in the catchment area of the cyclone trajectory deteriorates from 2007 to 2008 which represents the damage. The area at the centre of the eastern region, which has been mostly affected, represents a decreased NDVI value of 0-0.08 in 2008 from 0.24-0.29 in 2007 and according to the unsupervised classification it was dominated by the floristic taxon types - Sundari, Gewa and Kewra. The other parts of the eastern region are also affected and the NDVI value decreases to 0.08-0.16 in 2008 from 0.16-0.24 in 2007.

The NDVI image of February 2009 (Figure 5) represents a tendency of initial regeneration of the Sundarbans. The area in the eastern region, which is mostly affected by the decreased NDVI value of $0-0.08$, represents an increased NDVI value of 0.16-0.24. And at the south-eastern region, it represents even a faster regeneration and represents the higher NDVI value of 0.24-0.29. The western region represents a decreased NDVI value than that of 2008, which reflects the decrease of the floristic taxon cluster 1 in the unsupervised classified images.

The final NDVI image of February 2010 (Figure 5) represents a blooming stage of Sundarban with healthy biomass. Most of its area represents the NDVI value of 0.42-0.54, which is not identifiable in the NDVI maps of other years. The remaining part of the region is dominated by the high NDVI value of $0.34-0.42$, which represents a higher regeneration of the Sundarbans from the effects of cyclone Sidr, during 2009-2010 than during 2008-2009.

The frequency distribution of the pixels assigned to different NDVI values (Figure 6) represents the quantified 
damage and regeneration more clearly. From the frequency distribution of February 2007 and 2008 (Figure 6), it is apparent that the number of pixels with the NVDI value of 0.24-0.29 are drastically decreased (from count $1,600,000$ to count 850,000 ) from 2007 to 2008 which is compensated by the increase in the NDVI value classes of $0-0.08$ (from count 400,000 to $2,150,000$ ) and $0.08-0.16$ (from count 825,000 to count 1,000,000). Pixels with the value $0.29-0.34$ are also drastically decreased (from count 1,400,000 to almost count 800,000) because of the cyclone effect. In a nutshell, the number of pixels with low NDVI values is increased from 2007 to 2008 while the number of pixels with high NDVI values is decreased especially in the cyclone trajectory catchment areas, which represents the extent of damage due to the cyclone.

Whereas, the frequency distribution of the pixels of the NDVI images of February 2008 and 2009 (Figure 6) represents an increase in the number of pixels of the NDVI values in 2009, which experienced a decrease from 2007 to 2008. The number of pixels with the NDVI values of 0.16-0.24 and 0.24-0.29 is increased to count $1,200,000$ and 1,700,000 respectively. It represents the initial regeneration of the Sidr affected areas. And the final comparison of the pixel distribution of February 2009 and 2010 (Figure 6) reveals that the pixels with the higher value classes (0.34-0.42 and 0.42-0.54) are increased significantly, which represents remarkable regeneration of the flora during 2009-2010. The number of pixels with the NDVI value of 0.34-0.42 is increased by count $1,700,000$, and the change in the number of pixels with the NDVI value is noteworthy i.e. from average count 250,000 to count $2,300,000$.

The area coverage by different NDVI values in between 2007 and 2010 are calculated and presented in Figure 7. In February 2007, the largest area of the Sundarbans flora represents the NDVI value between 0.16-0.34. After the cyclone damage, in February 2008 the NDVI value of the largest floristic area turns into $0-0.08$, which represents the destructed and unhealthy state of the vegetation. In February 2009, the domination of the NDVI value of 0.29-0.34 can be recognised as a signature of regeneration. The largest area coverage of the NDVI value range of $0.34-0.54$ in February 2010 represents the healthy biomass of the Sundarbans and complete recovery from the cyclone damage.

The increase and decrease in the area coverage of different NDVI value in the pre and post cyclone period are presented in Table 1. In the post-cyclone period, the area coverage of the NDVI value range of 0.24-0.34, which is basically covering the catchments of the cyclone trajectory in the pre-cyclone period, decreases by $1200 \mathrm{sq} . \mathrm{km}$ Basically, from Figure 7, it is clear that there is a simultaneous increase in the coverage of this particular NDVI value range in the western part of the Sundarbans in 2008, which is not affected by the cyclone.

The decrease in the area coverage of the NDVI range represents the gross decrease in the area coverage of this particular NDVI range (Table 1). From the calculation of the area in the cyclone catchment, which is covered by the NDVI range of 0.24-0.34 in 2007 but is covered by the lower NDVI value in 2008 (Figure 5), the result of the extent of cyclone damage is approximately 2500 sq. $\mathrm{km}$. This value represents around $45 \%$ of the total Sundarbans mangrove forest (Bangladesh part). 45\% of the damaged area with 0.24-0.29 NDVI coverage (351 sq.. $\mathrm{km}$ ) is regenerated from 2008 to 2009 (Table 1), whereas the damaged area with 0.29-0.34 NDVI coverage is regenerated to the full extent (Table 1 and Figure 5). The area coverage of NDVI value range of 0.34-0.54, which is mostly covering the western part of the Sundarbans in 2008, decreases by 45 sq.km. in 2009. In 2010, there is a significant $2943 \mathrm{sq} . \mathrm{km}$. increase in the area coverage of the NDVI value range of 0.34-0.54, which represents the healthy status of the vegetation, it is even healthier in 2010 than in 2007. By calculating the average increase and decrease in the area coverage of different NVDI value in the post-cyclone period from Table 1, it is found that the average growth rate of the Sundarbans vegetation in 2009-2010 is four times higher than the one in 2008-2009.

The degree of cyclone damage can neither be identified concretely from the NDVI analysis; it represents the change in the health of the leaves over time based on their photosynthetic accitvities. But a tree being without leaves and consequent low NDVI value do not represent the degree of its damage; it is subject to further hyperspectral remote sensing analysis. The replacement of the floristic taxon cluster 1 by the fallow land in 2008 (Figure 6) according to the unsupervised classification and the replacement of the NDVI value range of 0.24-0.34 by the less healthy NDVI value range of 0-0.08 (Figure 6) may represent the complete destruction of the floristic taxon cluster 1 in the catchments of the cyclone trajectory. But this is impossible since mangrove is slow growing vegetation (Baldwin et al., 2001; Komiyamaa et al., 2008; Smith, 1998) and most of the mangrove seedlings need at least 10 years to be matured. Therefore, a complete destruction of floristic taxon cluster 1 and its regeneration within 1 year (by 2009) is merely impossible. Ground data based studies (Hossain \& Begum, 2011) claim that at least 1 tree per 100 sq.m. is broken or uprooted by the cyclone Sidr. Comparing the result of our study to this study represents that there is no complete destruction of any floristic taxon type due to cyclone Sidr but the damage is significant. In light of the studies of the cyclone effect on other mangroves (Nayak et al., 
2001), it can be concluded that most of the mangrove tress shed their leaves due to the cyclone Sidr. Some of them are uprooted but the nature was able to recover the total damage in 1 year.

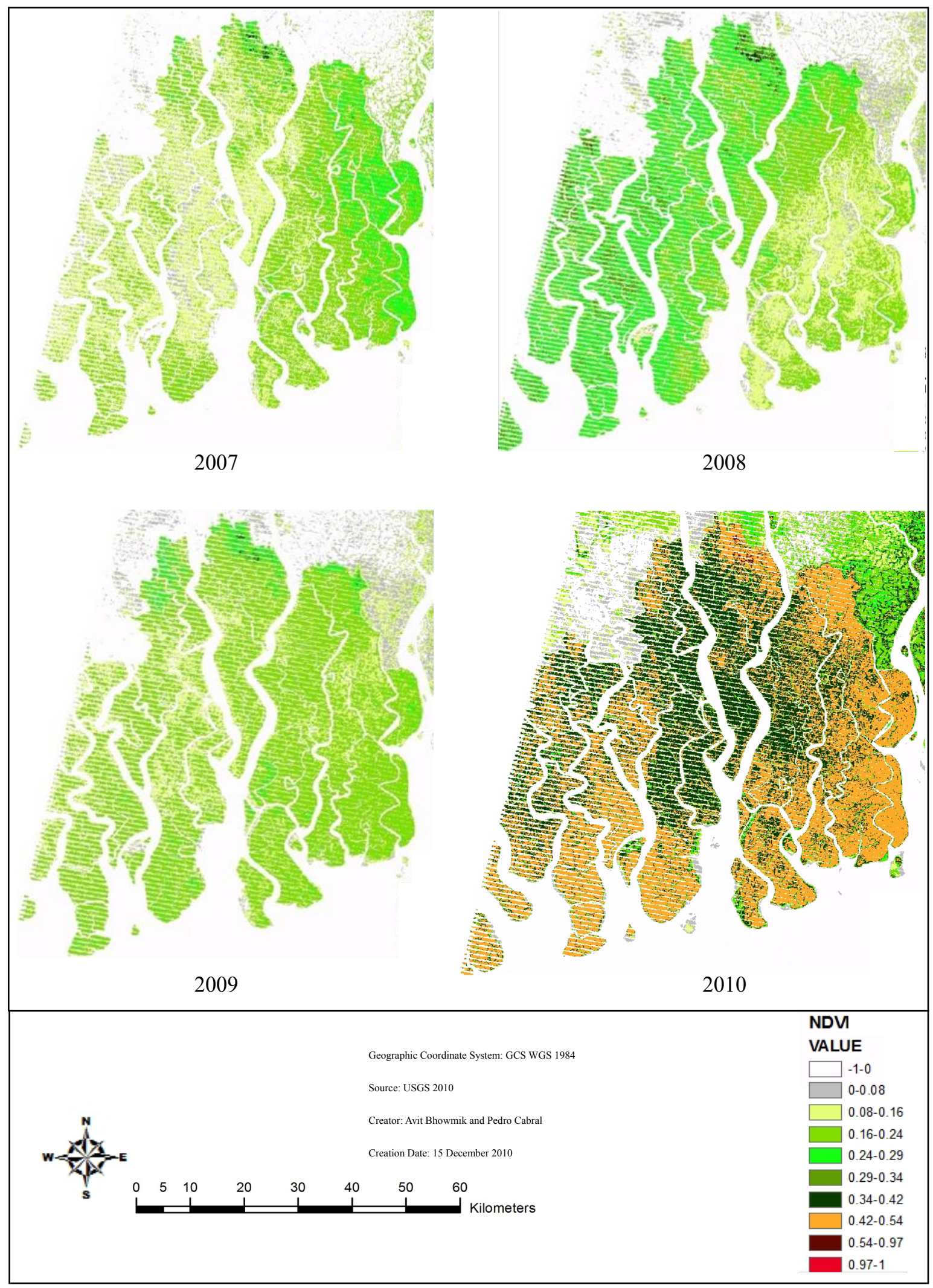

Figure 5. NDVI map of the Sundarbans in February 2007, 2008, 2009 and 2010 


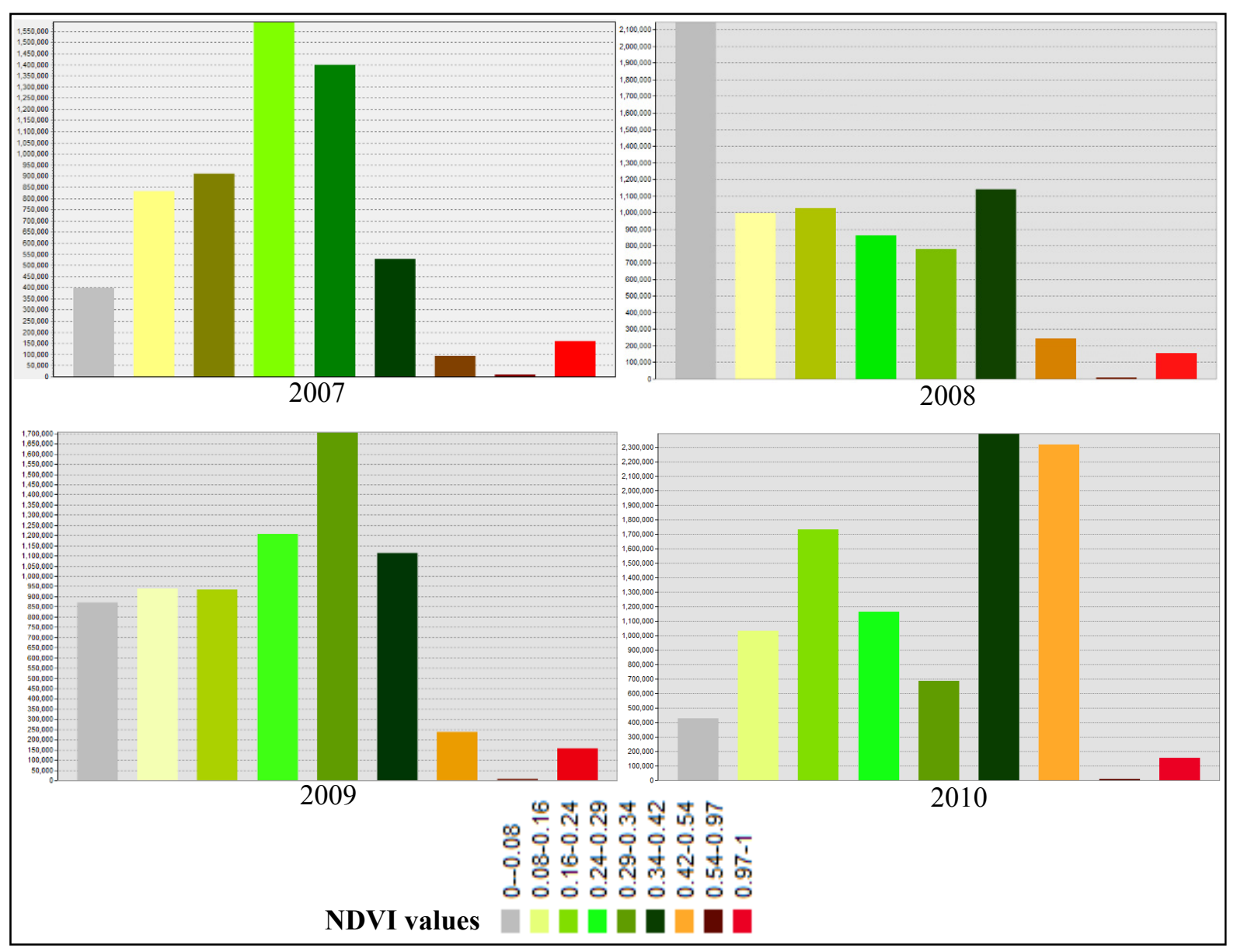

Figure 6. The frequency distribution of the pixels assigned to each NDVI class in February 2007, 2008, 2009 and 2010

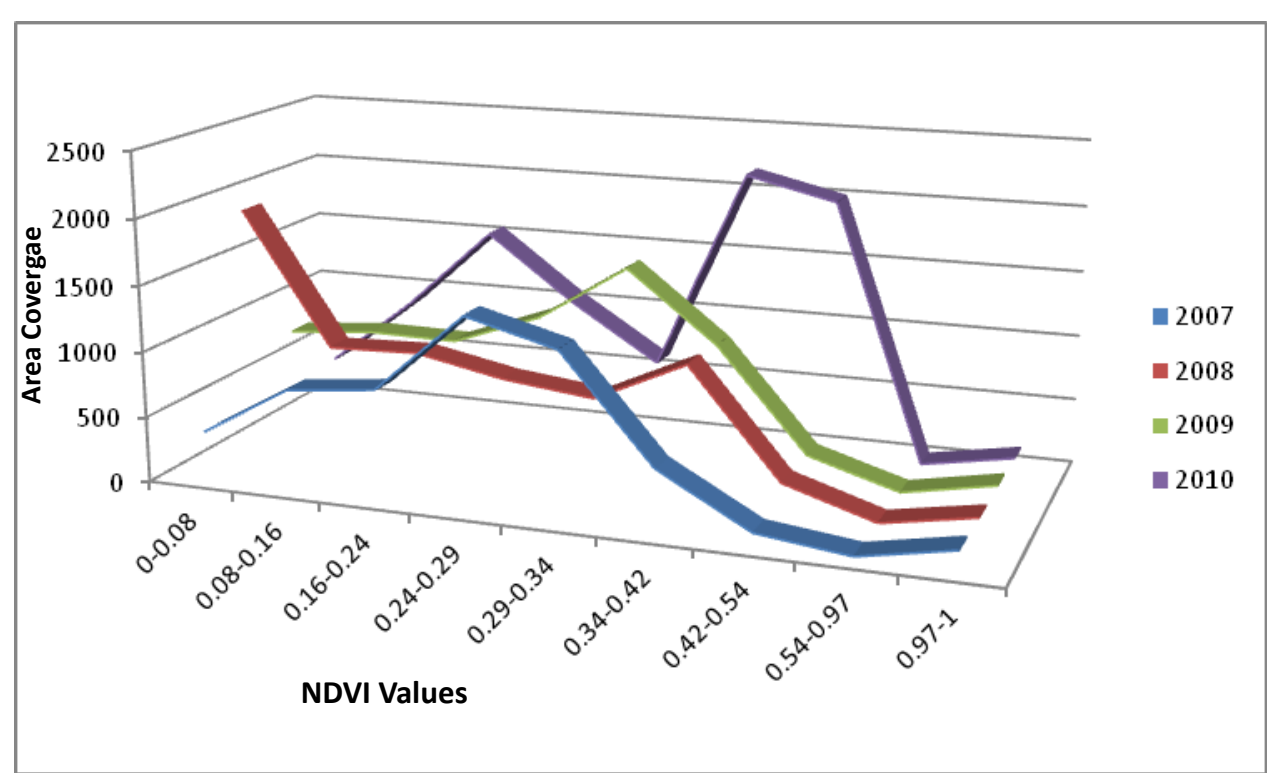

Figure 7. The area coverage of different NDVI values resulted in the images of February 2007, 2008, 2009 and 2010 
Table 1. Change in the areas' coverage of each NDVI value range from 2007 to 2010

\begin{tabular}{|c|c|c|c|}
\hline NDVI Values & $\begin{array}{l}\text { From February } 2007 \\
\text { to February } 2008\end{array}$ & $\begin{array}{l}\text { From February } 2008 \\
\text { to February } 2009\end{array}$ & $\begin{array}{l}\text { From February } 2009 \\
\text { to February } 2010\end{array}$ \\
\hline $0-0.08$ & Increase of $1553 \mathrm{sq} . \mathrm{km}$. & Decrease of 1125 sq. km. & Decrease of 410 sq. $\mathrm{km}$. \\
\hline $0.08-0.16$ & Increase of 144 sq. km. & Decrease of 54 sq. km. & Increase of 72 sq. km. \\
\hline $0.16-0.24$ & Increase of $95 \mathrm{sq} . \mathrm{km}$. & Decrease of 86 sq. km. & Increase of $711 \mathrm{sq} . \mathrm{km}$ \\
\hline $0.24-0.29$ & Decrease of 652 sq. km. & Increase of $301 \mathrm{sq} . \mathrm{km}$. & Decrease of 45 sq. km. \\
\hline $0.29-0.34$ & Decrease of 549 sq. km. & Increase of 819 sq. km. & Decrease of 918 sq. km. \\
\hline $0.34-0.42$ & Increase of 562 sq. km. & Decrease of 36 sq. km. & Increase of $1161 \mathrm{sq} . \mathrm{km}$. \\
\hline $0.42-0.54$ & Increase of 135 sq. km. & Decrease of 9 sq. km. & Increase of 1782 sq. km. \\
\hline $0.54-0.97$ & No Change & No Change & No Change \\
\hline $0.97-1$ & Decrease of 9 sq. $\mathrm{km}$. & Increase of 9 sq. $\mathrm{km}$. & Decrease of 9 sq. $\mathrm{km}$. \\
\hline
\end{tabular}

\subsection{Accuracy Assessment}

Accuracy assessment is performed according to the process described in the methodology section (section 3.6) and the results are presented in Table 2-5. The accuracy of the obtained results according to the scope of this study is satisfactory; the majority of the classified pixels represent the same spectral signature as of the reference dataset according to the confusion matrices (Table 2 and Table 3). The overall accuracy obtained from the confusion matrices of the unsupervised-classified and NDVI images of the study area are $76 \%$ and $88 \%$, respectively, which is an acceptable accuracy of the image classification (Tables 4 and 5). The confusion matrix for the unsupervised classification (Table 2) represents a low producer's accuracy $(50 \%)$ for floristic taxon cluster 1 (Table 4). The user's accuracy of the floristic taxon cluster 2 is also low (68\%). It is important to mention that in unsupervised classification, the floristic taxon cluster 1 has often been classified as the floristic taxon cluster 2 and vice versa. The lower accuracies may result from this phenomenon which is highly likely for the available spectral resolution of the image. On the other hand, the confusion matrix of NDVI (Table 3) determines $100 \%$ user accuracy for fallow land and water and $100 \%$ producer accuracy for the Sundarbans vegetation (Table 5). The accuracy results for the other landuse types are also satisfactory. This means the omission and commission errors have been minimized in NDVI images, which implies that the quantification of the extent of the damage and rate of regeneration from the NDVI image analysis should be satisfactorily accurate.

Table 2. Confusion matrix for the classified map of February 2007

\begin{tabular}{lrrrr}
\hline & Species type 1 & Species type 2 & Water & Row total \\
\hline Species type 1 & 9 & 9 & 0 & 18 \\
Species type 2 & 3 & 19 & 0 & 22 \\
Water & 0 & 0 & 10 & 10 \\
Column total & 12 & 28 & 10 & 50 \\
\hline
\end{tabular}

Table 3. Confusion matrix for the NDVI map of February 2010

\begin{tabular}{lrrrrr}
\hline & Fallow land & Sundarban Vegetation & Other Vegetation & Water body & Total \\
\hline Fallow Land & 2 & 0 & 1 & 0 & 3 \\
Sundarban Vegetation & 0 & 30 & 0 & 0 & 30 \\
Other Vegetation & 0 & 2 & 4 & 0 & 6 \\
Waterbody & 0 & 3 & 0 & 8 & 11 \\
Total & 2 & 35 & 5 & 8 & 50 \\
\hline
\end{tabular}


Table 4. Accuracy obtained from the classified image of February 2007

\begin{tabular}{lrr}
\hline Overall accuracy $=76 \%$ & & \\
\hline Class & Producer's Accuracy (\%) & User's Accuracy (\%) \\
\hline Species type 1 & 50 & 75 \\
Species type 2 & 86.36 & 67.86 \\
Water & 100 & 100 \\
\hline
\end{tabular}

Table 5. Accuracy obtained from the NDVI Map of February 2010

\begin{tabular}{lrr}
\hline Overall Accuracy $=88 \%$ & & \\
\hline Classes & Producer's Accuracy (\%) & User’s Accuracy (\%) \\
\hline Fallow Land & 66.67 & 100 \\
Sundarban Vegetation & 100 & 85.71 \\
Other Vegetation & 66.67 & 80 \\
Waterbody & 72.73 & 100 \\
\hline
\end{tabular}

\section{Discussion}

In light of the accuracy, the extent of the damage of the Sundarbans vegetation can be anchored to $2500 \mathrm{sq} . \mathrm{km}$. (according to NDVI analysis) from this study though the resulted extent of damage from the unsupervised classification is somehow lower (1728 sq.km.). This result is also supported by the ground data based studies (CEGIS, 2007; Hasegawa, 2010; Hossain \& Begum, 2011; Paul \& Dutt, 2010). On the contrary, the affected vegetation types are only identifiable from the unsupervised classification: Sundari (Heritiera fomes), Gewa (Excoecaria agallocha) and Kewra (Sonneratia apetala). Sundari is the most important floristic taxon of the Sundarbans and therefore the cyclone has a major impact on the degradation of the floristic diversity of the forest. The species in the floristic taxon cluster 1, which grew in the cylone catchment area are also affected, but the analysis could not identify them. The degree of the damage is identifiable neither by the unsupervised classification nor by the NDVI analysis, but the time required for the initial regeneration islyear (according to the temporal resolution of the images). In addition, the average vegetation growth rate is resulted to be four times higher during 2009-2010 than the one during 2008-2009 from the analysis of the general health of the biomass.

The extent of cyclone damage and average rate of vegetative growth are quantified basically from the NDVI analysis. Therefore precipitation in the wet seasons of these years of the Sundarbans area should also be taken into account because the amount of precipitation influences the spectral reflectance of the leaves and corresponding NDVI results (Julien et al., 2011). The meteorological station at Khulna measured $7104 \mathrm{~mm}, 5913$ $\mathrm{mm}, 6212 \mathrm{~mm}$ and $4227 \mathrm{~mm}$ of precipitation in the wet seasons of 2007, 2008, 2009 and 2010 respectively (DMIC-CDMP, 2012). In contrast to these precipitation values, the NDVI results illustrate the cyclone damage and floristic growth appropriately. Though the precipitation amount decreased from 2007 to 2008, the NDVI values decrease only in the cyclone affected area of the Sundarbans in the image. Similarly, the decrease in the NDVI values in the western region from 2008 to 2009 is also not influenced by the general increase in the precipitation amount during 2008-2009. And the overall increase in the NDVI values of the Sundarbans from 2009 to 2010 does not reflect the decrease in the precipitation amount. Therefore, the changes in the NDVI values represent the extent of cyclone damage and rate of post cyclone regeneration, not the sensitivity of the steady biomass to the seasonal precipitation.

\section{Final Remarks}

This study has quantified the extent of cyclone Sidr damage of the Sundarbans applying remote sensing techniques on freely and quickly available Landsat imageries. On one hand, it is true that ground data based studies are more accurate but they require more time, human and logistic resources. This study has provided realistic results that other ground data based studies took several years to obtain. It is shown that the extent of the cyclone Sidr damage, which is 2500 sq.km., could already been obtained in 2008 using this analysis; which has been published by the ground data based studies in 2011. Therefore these methods can be applied in case of emergency decision making about the mangrove forests after the cyclone. Parallely, this study can be used for 
primary analysis of the extent of damage and detailed ground data based analysis can be in further carried out on the specific locations that turn out to be significant from the primary analysis. Eventually it will save a lot of time and resources and foster the recovery endeavors. On the other hand, sensors with high spatial, spectral and temporal resolution, e.g. Quickbird and their imageries may result in more specific and detailed damage and regeneration analyses but they are hardly available for the countries like Bangladesh due to techno-economic reasons. The Landsat ETM+ has some serious errors like the periodic line drop error experienced in this study, but it provides with the imageries with satisfactory spatial, temporal and spectral resolution, which are highly applicable in disaster management and floristic diversity analyses after minimizing these errors.

The periodic line drop error could not be ignored even after the image-preprocessing. In unsupervised classification, the edges of the scan lines especially have seemed to be assigned a class that is different from the adjacent whole above and below, which is very unlikely according to the ground truth. Further, results of the clustering of floristic taxon types from classified image have been prone to subjectivity. It would be more appropriate if more updated ground truth data were available as auxiliary dataset. The uncertainty of the frequency distribution of the pixels is also significant due to the inherent limitations of the sensor. The images are not acquired exactly at the same location. There is a deviation in the number of 'nodata' pixels in every year, thus the other pixels should follow the same.

Nevertheless the average rate of growth of the affected vegetation types resulted from the analysis corresponds with the characteristics of the species; Sundari, Gewa and Kewra experience slow growth rate in the primary stage of regeneration but the growth is very fast at the later stages (Hussain \& Ahmed, 1994). Though the number of reference points (50) collected for the accuracy assessment could be increased, the accuracy of the results is coherent with the reference dataset and an unbiased and sparse distribution of the reference points have been performed. Therefore, it could be concluded that although cyclone Sidr has brought significant damage to the floristic diversity of the world's largest mangrove forest, it has regenerated to a satisfactory condition in a very short period of time.

It has been proclaimed that neither the unsupervised classification nor the NDVI analysis of the imageries could quantify the degree of damage by the cyclone Sidr. But the time required by particular floristic types for satisfactory regeneration has been identified from this analysis. Thus the degree of regeneration can be subjected to further floristic studies, i.e., which is the damage state of the particular floristic type that can be regenerated in the resulted recovery time? And last but not the least; such approaches can be applicable in monitoring the floristic growth of the Sundarbans mangrove forest, which lacks intensive studies because of the techno-economic reasons. Finally, in light of this study, the cyclone Sidr has caused a temporary loss of floristic diversity to the Sundarbans mangrove forest for three years since the relative abundance of the three floristic taxa - Sundari, Gewa and Kewra has been temporarily decreased after that exogenous perturbation. This study's results will provide with the base for further long-term studies on this world's largest mangrove forest.

\section{Acknowledgements}

This study has been carried out in the framework of the European Commission, Erasmus Mundus Programme, M.Sc. in Geospatial Technologies, project NO. 2007-0064. René de Groot and M. Abdullah Abu Diyan have contributed by sharing their expert knowledge of ground studies, remote sensing, photosynthetic activity of mangrove species and mangrove species distribution in the Sundarbans. Professor Mário Caetano, Professor Nilanchal Patel and António Nunes have contributed by providing technical know-how about earth observation and remote sensing.

\section{References}

Andrew, J., \& Elmore, J. F. (2000). Quantifying Vegetation Change in Semiarid Environments: Precision and Accuracy of Spectral Mixture Analysis and the Normalized Difference Vegetation Index. Remote Sensing of Environment, 2000, 87-102. http://dx.doi.org/10.1016/S0034-4257(00)00100-0

Baldwin, A., Egnotovich, M., Ford, M., \& Platt, W. (2001). Regeneration in fringe mangrove forests damaged by Hurricane Andrew. Plant Ecology, 157(2), 151-164. http://dx.doi.org/10.1023/A:1013941304875

Barrett, E. C., \& Curtis, L. F. (1999). Introduction to environmental remote sensing. Cheltenham: Stanley Thornes Ltd.

Brink, A. B., \& Hugh, D. E. (2009). Monitoring 25 years of land cover change dynamics in Africa: A sample based remote sensing approach. Applied Geography, 29(4), 501-512. http://dx.doi.org/10.1016/j.apgeog.2008.10.004

Center for Environmental and Geographic Information Services Bangladesh (CEGIS). (2007). Effect of cyclone 
Sidr on the Sundarbans. A Preliminary Assessment.

Chaudhuri, A. B., Choudhury, A., Hussain, Z., \& Acharya, G. (1994). Mangroves of the Sundarbans. Volume 2: Bangladesh. In Z. Hussain, \& G. Acharya (Eds.), World Conservation Union (IUCN), Bangkok (Thailand). South-East Asia Regional Office: IUCN. http://dx.doi.org/10.1007/s00027-006-0868-8

Chuvieco, E., \& Congalton, R. G. (1989). Application of remote sensing and geographic information systems to forest fire hazard mapping. Remote Sensing of Environment, 29(2), 147-159. http://dx.doi.org/10.1016/0034-4257(89)90023-0

Conghe, S. C. E. (2001). Classification and Change Detection Using Landsat TM Data: When and How to Correct Atmospheric Effects? Remote Sensing of Environment, 203-244. http://dx.doi.org/10.1016/S0034-4257(00)00169-3

Dahdouh-Guebas, F. (2002). The use of remote sensing and gis in the sustainable management of tropical coastal ecosystems. Environment, Development and Sustainability, 4, 93-112. http://dx.doi.org/10.1023/A:1020887204285

Disaster Management Information Center (DMIC) of Comprehensive Disaster Management Program (CDMP). (2012). Bangladesh Meteorological Department. Retrieved January 23, 2012, from http://www.bmd.gov.bd/index.php

Eastman, J. R., \& Fulk, M. (1993). Long sequence time-series evaluation using standardized principal components. Photogramm. Eng. Remote Sensing, 59, 991-996.

Elsner, J. B., Kossin, J. P., \& Jagger, T. H. (2008). The increasing intensity of the strongest tropical cyclones. Nature, 455, 92-95. http://dx.doi.org/10.1038/nature07234

Emch, M., \& Peterson, M. (2006). Mangrove Forest Cover Change in the Bangladesh Sundarbans from 1989-2000: A Remote Sensing Approach. Geocarto International, 21(1), 5-12. http://dx.doi.org/10.1080/10106040608542368

ESRI. (2012). ArcGIS (Desktop, Engine, Server) 9.3.1 Service Pack 2. Retrieved April 30, 2012, from $\mathrm{http} / / /$ resources.arcgis.com/content/patches-and-service-packs?fa=viewPatch\&PID=66\&MetaID $=1620$

Fensholt, R., Rasmussen, K., Nielsen, T. T., \& Mbow, C. (2009). Evaluation of earth observation based long term vegetation trends-Intercomparing NDVI time-series trend analysis consistency of Sahel from AVHRR GIMMS, Terra MODIS and SPOT VGT data. Remote Sens. Environ., 113, 1886-1898. http://dx.doi.org/10.1016/j.rse.2009.04.004

Foody, G. M. (2003). Remote sensing of tropical forest environments: towards the monitoring of environmental resources for sustainable development. International journal of remote sensing, 24(20), 4035-4046. http://dx.doi.org/10.1080/0143116031000103853

Fuller, D. O. (2006). Tropical forest monitoring and remote sensing: A new era of transparency in forest governance? Singapore Journal of Tropical Geography, 27(1), 15-29. http://dx.doi.org/10.1111/j.1467-9493.2006.00237.x

Galford, G. L., Mustard, J. F., Melillo, J., Gendrin, A., Cerri, C. C., \& Cerri, C. E. P. (2008). Wavelet analysis of MODIS time-series to detect expansion and intensification of row-crop agriculture in Brazil. Remote Sensi. Environ., 112, 576-587. http://dx.doi.org/10.1016/j.rse.2007.05.017

Gibbs, H. K., Brown, S., Niles, J. O., \& Foley, J. A. (2007). Monitoring and estimating tropical forest carbon stocks: making REDD a reality. Environmental Research Letters, 2(4), 1-13. http://dx.doi.org/10.1088/1748-9326/2/4/045023

Giri, C., Pengra, B., Zhu, Z., Singh, A., \& Tieszen, L. L. (2007). Monitoring mangrove forest dynamics of the Sundarbans in Bangladesh and India using multi-temporal satellite data from 1973 to 2000. Estuarine, Coastal and Shelf Science, 73(1-2), 91-100. http://dx.doi.org/10.1016/j.ecss.2006.12.019

Gopal, B., \& Chauhan, M. (2006). Biodiversity and its conservation in the Sundarban Mangrove Ecosystem. Aquatic Sciences - research across boundaries, 68(3), 338-354. http://dx.doi.org/10.1007/s00027-006-0868-8

Hasegawa, K. (2010). Features of Super Cyclone Sidr to Hit Bangladesh in Nov., 07 and Measures for Disasterfrom Results of JSCE Investigation. Foundation of River \& Watershed Environment Management, Hokkaido Office, Sapporo, Japan. 
Hossain, M. Z., \& Begum, M. (2011). Vegetation of Sunderban Mangrove Foest after the Devastating Cyclone Sidr in Bangladesh. Society \& Change, 5(3), 72-78.

Hussain Z., \& Ahmed, I. (1994). Management of Forest Resources. In Z. Hussain \& G. Acharya (Eds.), Mangroves of the Sundarbans Volume Two: Bangladesh. International Union for Conservation of Nature and Natural Resources, Bangkok, 154-196. http://dx.doi.org/10.1007/s00027-006-0868-8

Iftekhar, M. S., \& Islam, M. R. (2004). Degeneration of Bangladesh's Sundarbans mangroves: a management issue. International Forestry, Review, 6(2), 123-135. http://dx.doi.org/10.1505/ifor.6.2.123.38390

Intergraph Corporation Part of Hexagon Group (ICPHG). (2012). Erdas Imagine. Retrieved April 30, 2012, from http://www.erdas.com/products/ERDASIMAGINE/ERDASIMAGINE/Details.aspx

Janssen, L. L. F., \& Van der Wel, F. J. M. (1994). Accuracy assessment of satellite derived land-cover data: a review. Photogrammetric engineering and remote sensing, 60(4), 419-426.

Jensen, J. R. (1996). Introductory Digital Image Processing: A remote sensing perspective. In K. C. Clarke (Ed.), Geographic Information Science. New Jersey: Prentice Hall. http://dx.doi.org/10.1080/10106048709354084

Julien, Y., Sobrino, J. A., Mattar, C., Ruescas, A. B., Jimenez-Munoz, J. C., Soria, G., ... Cuenca, J. (2011). Temporal analysis of normalized difference vegetation index (NDVI) and land surface temperature (LST) parameters to detect changes in the Iberian land cover between 1981 and 2001. International Journal of Remote Sensing, 32(7), 2057-2068. http://dx.doi.org/10.1080/01431161003762363

Kates, R. W., Clark, W. C., Corell, R., \& Hall, J. M. C. (2001). Sustainability science. Science, 292, 641-642. http://dx.doi.org/10.1126/science.1059386

Khorram, S., Biging, G. S., Chrisman, N. R., Colby, D. R., Congalton, R. G., Dobson, J. E., ... Mace, T. H. (1999). Accuracy assessment of remote sensing-derived change detection. Bethesda: ASPRS Monograph.

Komiyamaa, A., Ongb, J. E., \& Poungparnc, S. (2008). Allometry, biomass, and productivity of mangrove forests: A review. Aquatic Botany, 89(2), 128-137. http://dx.doi.org/10.1016/j.aquabot.2007.12.006

Li, A., Deng, W., Liang, S., \& Huang, C. (2010). Investigation on the Patterns of Global Vegetation Change Using a Satellite-Sensed Vegetation Index. Remote Sens., 2(6), 1530-1548. http://dx.doi.org/10.3390/rs2061530

Lin, I., Liu, W., T., Wu, C., Wong, G. T. F., Hu, C., Chen, Z., .. Liu, K. K. (2003). New evidence for enhanced ocean primary production triggered by tropical cyclone. Geophysical Research Letters, 30(13), 1718. http://dx.doi.org/10.1029/2003GL017141

Liu, C., Frazier, P., \& Kumar, L. (2007). Comparative assessment of the measures of thematic classification accuracy. Remote Sensing of Environment, 107(4), 606-616. http://dx.doi.org/10.1016/j.rse.2006.10.010

Mohaiman, R., Runkel, M., \& Khan, F. I. (2002). Sundarban Biodiversity Conservation Project. Bangladesh Forest Department, RIMS-GIS Unit, Dhaka.

Mumby, P. J., Green, E. P., Edwards, A. J., \& Clark, C. D. (1999). The cost-effectiveness of remote sensing for tropical coastal resources assessment and management. Journal of Environmental Management, 55, 157-166, Academic Press. http://dx.doi.org/10.1006/jema.1998.0255

Nayak, S. R., Sarangi, R. K., \& Rajawat, A. S. (2001). Application of IRS-P4 OCM data to study the impact of cyclone on coastal environment of Orissa. CURRENT SCIENCE, 80(9), 1208-1213.

Oja, H. (1983). Descriptive statistics for multivariate distributions. Statistics \& Probability Letters, 1(6), 327-332. http://dx.doi.org/10.1016/0167-7152(83)90054-8

Paul, B. (2009). Why relatively fewer people died? The case of Bangladesh's Cyclone Sidr. Natural Hazards, 50(2), 289-304. http://dx.doi.org/10.1007/s11069-008-9340-5

Paul, B. K., \& Dutt, S. (2010). Hazard Warnings and Responses to Evacuation Orders: The Case of Bangladesh's Cyclone Sidr. Geographical Review, 100, 336-355. http://dx.doi.org/10.1111/j.1931-0846.2010.00040.x

Rogan, J., \& Chen, D. M. (2004). Remote sensing technology for mapping and monitoring land-cover and land-use change. Progress in Planning, 61, 302-325. http://dx.doi.org/10.1016/S0305-9006(03)00066-7

Rouse, J. W., Haas, R. H., Schell, J. A., \& Deering, D. W. (1973). Monitoring vegetation systems in the Great Plains with ERTS. Third ERTS Symposium, NASA SP-351(I), 309-317.

Salovaara, K. J., Thessler, S., Malik, R. N., \& Tuomisto, H. (2005). Classification of Amazonian primary rain 
forest vegetation using Landsat ETM+ satellite imagery. Remote Sensing of Environment, 97(1), 39-51. http://dx.doi.org/10.1016/j.rse.2005.04.013

Shamsuddoha, Md. \& Chowdhury, R. K. (2007). Climate Change Impact and Disaster Vulnerabilities in the Coastal Areas of Bangladesh. COAST Trust, Equity and Justice Working Group (EJWG).

Skidmore, A. K., Bijker, W., Schmidt, K., \& Kumar, L. (1997). Use of remote sensing and GIS for sustainable land. ITC Journal, 3(4), 302-315.

Smith, G. M. (1998). Assessing seasonal vegetation change in coastal wetlands with airborne remote sensing: an outline methodology. Mangrove and Salt Marshes, 2(11), 15-28. http://dx.doi.org/10.1023/A:1009964705563

Stork, N. E., Boyle, T. J. B., Dale, V., Eeley, H., Finegan, B., Lawes, M., ... Soberonet, J. (1997). Criteria and Indicators for Assessing the Sustainability of Forest Management: Conservation of Biodiversity. Working Paper, CENTER FOR INTERNATIONAL FORESTRY RESEARCH, Sindangbarang, Bogor 16680, Indonesia: SMT Grafika Desa Putera.

Story, M., \& Congalton, R. G. (1986). Accuracy assessment: a user's perspective. Photogrammetric Engineering and Remote Sensing, 52(3), 397-399.

Tucker, C. J. (1979). Red and photographic infrared linear combinations for monitoring vegetation. Remote Sens. Environ., 8, 127-150. http://dx.doi.org/10.1016/0034-4257(79)90013-0

US Department of State Geographer (USSG). (2010). Google Earth, Europa Technologies, GeoEye. Rerieved November 11, 2010, from http://eros.usgs.gov/\#/Find_Data/Products_and_Data_Available/ETM

USGS Earth Resources Observation and Science (EROS) Center. (2010). Landsat Enhanced Thematic Mapper Plus (ETM+). $\quad$ Retrieved October 1, 2010, from http://eros.usgs.gov/\#/Find_Data/Products_and_Data_Available/ETM

Wolter, P. T., Mladenoff, D. J., Host, G. E., \& Crow, T. R. (1995). Impproved Forest Classification in the Northern Lake States Using Multi-Temporal Landsat Imagery. Photogrammetric Engineering \& Remote Sensing, 61(9), 1129-1143.

Wood, J. E., Gillis, M. D., Goodenough, D. G., Hall, R. J., Leckie, D. G., Luther, J. E. \& Wulder, M. A. (2002). Earth Observation for Sustainable Development of Forests (EOSD): project overview. Geoscience and Remote Sensing Symposium, 2002. IGARSS '02. 2002 IEEE International, 3, 3694. http://dx.doi.org/10.1109/IGARSS.2002.1026097

Yale University. (2010). Unsupervised Classification Algorithms 2010. Retrieved December 8, 2010, from http://www.yale.edu/ceo/Projects/swap/landcover/Unsupervised_classification.htm 